\title{
Combined Effect of Methanol Extracts and Essential Oils of Callistemon rigidus (Myrtaceae) and Eucalyptus camaldulensis (Myrtaceae) against Anopheles gambiae Giles larvae (Diptera: Culicidae)
}

\author{
Lame Younoussa $\left(\mathbb{D},{ }^{1,2}\right.$ Francine Kenmoe, ${ }^{3}$ Mallam Kary Oumarou, ${ }^{3}$ \\ Aurore Christelle Sengue Batti, ${ }^{2}$ Joseph Lebel Tamesse, ${ }^{4}$ and Elias Nchiwan Nukenine $\mathbb{C D}^{3}$ \\ ${ }^{1}$ Institute of Medical Research and Medicinal Plants Studies, P.O. Box 13033, Yaoundé, Cameroon \\ ${ }^{2}$ Department of Animal Biology and Physiology, Faculty of Science, University of Yaounde 1, P.O. Box 812, Yaounde, Cameroon \\ ${ }^{3}$ Department of Biological Sciences, Faculty of Science, University of Ngaoundéré, P.O. Box 454, Ngaoundere, Cameroon \\ ${ }^{4}$ Department of Biological Sciences, Higher Teacher's Training College, University of Yaounde I, P.O. Box 47, Yaounde, Cameroon
}

Correspondence should be addressed to Lame Younoussa; younoussalame@yahoo.com

Received 2 October 2019; Accepted 8 February 2020; Published 28 April 2020

Academic Editor: João Pedro Barreiros

Copyright ( 2020 Lame Younoussa et al. This is an open access article distributed under the Creative Commons Attribution License,
which permits unrestricted use, distribution, and reproduction in any medium, provided the original work is properly cited.

Biopesticides from botanicals are nowadays actively encouraged in the mosquito control program because of their low mammalian toxicity, biodegradability, and target specificity. However, leaf methanolic extracts and essential oils of Callistemon rigidus and Eucalyptus camaldulensis were evaluated individually and in combination on third- and fourth-instar larvae of Anopheles gambiae. The extracts were tested individually and in combination at doses of 125, 250, 500, and $1000 \mathrm{ppm}$ while essential oils were applied at 25, 50, 100, and 200 according to the standard protocol of WHO. The commercial insecticide Bi-one tested at the recommended dose of $1000 \mathrm{ppm}$ was used as positive control while the solution of tap water containing $0.5 \mathrm{ml}$ of methanol was used as negative control. The mortality of the larvae was recorded after $24 \mathrm{~h}$ postexposure. In the results, $100 \%$ mortality of the larvae was recorded with the extracts of C. rigidus and the combinations E50\%:C50\% and E25\%:C75\% of the plants as well as positive control (1000 ppm). Similarly, essential oils of the two plants and their combinations caused $100 \%$ mortality of the larvae. Among the various combinations of the extracts and essential oils, only the combination E75\%: C25\% of essential oils presented a synergistic effect. Therefore, the essential oil combination (E75\%: C25\%) of the plants E. camaldulensis and C. rigidus is recommended in order to promote the its use in the form of natural biocide in the implementation of effective insect controls against the mosquito larvae, vector of malaria.

\section{Introduction}

In sub-Saharan Africa, malaria still remains one of the most dangerous diseases, responsible for the millions of deaths annually, and children under 5 years old, pregnant women, and persons with HIV/AIDS are the most unwell from that disease [1]. In 2017, approximately 219 million cases were reported with 435,000 deaths recorded from the disease [2]. That deathful disease caused by the Plasmodium spp parasites is transmitted to humans through the bites of mosquitoes belonging to the genera of Anopheles, and the mosquito species Anopheles gambiae Giles is the main vector of malaria in the sub-Saharan African countries. However, current methods put in place to tackle malaria are facing problems of drug side effects expressed in the patients and the development of parasite resistance to drugs currently in use for treatment. Besides, no licensed malaria vaccine exists since numerous malaria vaccine candidates (more than 30 Plasmodium falciparum vaccines) targeting either preerythrocytic, blood, or sexual stages of the parasite life cycle are still under clinical trials $[3,4]$. For that, vector control remains the best method to 
lower the rate of disease transmission in the population. Unfortunately, insect vector control is also facing numerous difficulties because of the misuse of synthetic insecticides in agriculture and insect pest control programmes leading to environmental pollution, causing an ecological imbalance. Specifically, the synthetic insecticides in use are toxic not only to humans but also to nontarget organisms without omitting the problem of the development of insecticide resistance and the resurgence of new pest species $[5,6]$. Thus, in recent years around the world, natural products raised the attention of researchers to look for new alternative solutions to reduce the excessive use of these synthetic pesticides. Among these alternatives of which nature presents, botanical-derived products are of particular interest since they are less toxic, biodegradable, and target-specific [7-9]. Plants are rich in bioactive chemical secondary metabolites and have proven their insecticidal activities by killing or repelling insects [10-13].

Native from Australia and belonging to the family of Myrtaceae, Eucalyptus camaldulensis is a high tree largely widespread in the word. The essential oil in this plant is rich in oxygenated and nonoxygenated monoterpenes as well as sesquiterpenes [14]. Previously, tannins, flavonoids, glycosides, and sterols were reported in different parts of that plant [15]. Several previous studies reported the mosquitocidal activity of Eucalyptus camaldulensis against Culex pipiens and Anopheles stephensi mosquito species [16-18].

Commonly called stiff bottlebrush, Callistemon rigidus (Myrtaceae) is a bushy tree with narrow, pointed, dark leaves and pink-red flowers, found wildly only in Australia and nowadays widespread worldwide. Cineol, flavone, flavonol, and triterpenoid are the major phytocomponents found in the essential oil of C. rigidus [19] while tannins and flavonoids are found in the leaves of the plant [20]. The toxic effect of $C$. rigidus essential oils was reported against Anopheles gambiae, Aedes aegypti, and Culex quinquefasciatus mosquito species [21]. The leaf extracts and fractions of the plant were also effective against the bean beetle Callosobruchus maculatus [22].

Synergistic effect of the combination of the plant extracts was widely documented in the literature, and plant combination might increase the efficacy instead of each single plant used and consequently may prevent insect resistance issues [23]. Described as any kind of positive interaction between drugs or insecticides, synergism can take place between the constituents of a single extract as well as in a mixture of herbs since herbalists have always insisted that better results are obtained with whole plant extracts and combinations of these rather than with isolated compounds [24]. To search for the improvement of the insecticidal efficacy of plant products and to prevent insecticide resistance problem, this present investigation aimed to assess the synergistic activity of the blend of methanol extracts and essential oils of Eucalyptus camaldulensis and Callistemon rigidus against the third- and fourth-instar larvae of the main malarial vector Anopheles gambiae in the laboratory conditions.

\section{Materials and Methods}

2.1. Plant Material Collection and Processing. The green leaves of Callistemon rigidus and Eucalyptus camaldulensis were harvested around the campus of the University of Ngaoundere, Cameroon, in December 2017 and identified by Prof. Pierre-Marie Mapongmetsem, botanist of the Faculty of Science, University of Ngaoundere, Cameroon. The leaves of the two plant species were shade-dried for 10 days at ambient laboratory conditions $\left(24 \pm 2^{\circ} \mathrm{C} ; 76 \pm 4 \% \mathrm{HR}\right)$, grounded in the wood mortar, and passed through $0.4 \mathrm{~mm}$ mesh size sieve. Each plant powder obtained was stored in the dark bottles at the ambient temperature until their extraction.

2.2. Plant Methanol Extraction. The methanol extract of each plant species was extracted by macerating $250 \mathrm{~g}$ of each plant powder in $2500 \mathrm{~mL}$ of methanol. The maceration was stirred twice a day and after $72 \mathrm{~h}$ and was filtered using Whatman paper No. 1. The methanol in the filtrate was evaporated in open air, and the dried methanol plant extract was stored in the dark glass at $4^{\circ} \mathrm{C}$ until its use for bioassay and phytochemical screening. The extraction yield was calculated by the following formula:

$$
\begin{aligned}
& \text { Methanol extraction yield (\%) } \\
& =\frac{\text { weight of the extract obtained }}{\text { weight of plant powder used }} \times 100 \text {. }
\end{aligned}
$$

2.3. Phytochemical Screening of the Methanol Extract. The methanol extracts of $C$. rigidus and E. camaldulensis were submitted to the qualitative phytochemical screening tests to identify some anti-insect phytochemical compounds including alkaloids, flavonoids, saponins, tannins, polyphenols, and terpenoids which, according to the literature, possess an insecticidal property. The methods performed by Harborne [25], Evans and Trease [26], and Prashant et al. [27] were performed to determine these phytocomponents targeted.

2.4. Extraction of Essential Oils. The essential oils of $C$. rigidus and E. camaldulensis were extracted by hydrodistillation process using Dean-Stark apparatus. Indeed, $200 \mathrm{~g}$ of green leaves of each plant species was mixed with $500 \mathrm{~mL}$ of distilled water and submitted to hydrodistillation procedure for $3 \mathrm{~h}$. Floral water and essential oil were separated using separating funnel, and traces of water in the essential oil were completely removed with anhydrous sodium sulfate. Each dried plant essential oil obtained was kept in dark glass and stored at $4^{\circ} \mathrm{C}$ until use for the test. The essential oil extraction yield was calculated using the following formula:

Essential oil extraction yield (\%)

$$
=\frac{\text { weight of the oil recovered }}{\text { weight of the fresh leaves used }} \times 100 \text {. }
$$


2.5. Mosquito Species. To establish the colony, eggs of the laboratory strain of Anopheles gambiae were collected from OCEAC at Yaounde, Cameroon, in February 2018. In the insectarium of the Laboratory of Applied Zoology of the University of Ngaoundere, mosquito eggs were transferred into the bucket containing tap water and the hatched larvae were reared according to the standard protocol of WHO [28]. Larvae were fed with TetraMin ${ }^{\circledR}$ (Tetra GmbH, Germany) and were maintained under ambient condition of the insectarium $\left(27 \pm 2^{\circ} \mathrm{C} ; 74 \pm 4 \%\right.$ r.h. $)$. Third and fourth instars of mosquito larvae were used for the experiments.

2.6. Larvicidal Bioassay. The larvicidal efficacy of the methanol extracts and essential oils of E. camaldulensis and $C$. rigidus tested singly or in binary combination against $A$. gambiae larvae was evaluated according to the standard protocol described by WHO [29]. The binary combinations of the methanol extracts or essential oils of E. camaldulensis with C. rigidus in proportions of $25 \%+75 \%, \quad 50 \%+50 \%$, and $75 \%+25 \%$ representing combinations of $\mathrm{E} 25 \%: \mathrm{C} 75 \%, \mathrm{E} 50 \%: \mathrm{C} 50 \%$, and $\mathrm{E} 75 \%$ : C25\%, respectively, were prepared. Plant methanol extracts and essential oils individually or in binary combination were dissolved in $0.5 \mathrm{~mL}$ of Tween-80, and concentrations of $125,250,500,1000$, and $2000 \mathrm{ppm}$ for plant methanol extracts and of 25, 50, 100, 200, and $400 \mathrm{ppm}$ for essential oils were prepared in the volume of $100 \mathrm{~mL}$ of solution in the plastic cups $(250 \mathrm{~mL})$. The negative control consisted to add $0.5 \mathrm{~mL}$ to $99.5 \mathrm{~mL}$ of tap water while $\mathrm{Bi}^{-}$one $^{\mathrm{TM}}(1000 \mathrm{ppm})$ was used as a positive control. A total of 25 third- and fourth-instar larvae were transferred into each solution test preparation, and each dose was repeated 4 times. Larval mortality was recorded after $24 \mathrm{~h}$ posttreatment, and larva was declared dead, if it is no longer moving even after pinching with an entomological needle. The larval mortality percentage was calculated and then corrected using Abbott [30] formula if the larval mortality percent in the negative control ranged between $5 \%$ and $20 \%$ according to the following formula:

$$
\begin{aligned}
& \text { Mortality percent }(\%)= \frac{\text { number of dead larvae }}{\text { total number of larvae used }} \\
& \times 100, \\
& \text { Corrected mortality percent }(\%)=\left[\frac{(\mathrm{NC}-\mathrm{NT})}{\mathrm{NC}}\right] \times 100,
\end{aligned}
$$

where $\mathrm{NC}=$ percentage of dead larvae in the control and $\mathrm{NT}$ = percentage of dead larvae in the test.

After the calculation of $\mathrm{LC}_{50}$ values of two plants extracts and essential oils tested singly or in combination, cotoxicity index of each combination was determined as follows:
Toxicity index (TI) of E $=100$ and toxicity index (TI) of C

$$
\begin{aligned}
= & {\left[\frac{\mathrm{LC}_{50} \text { of } \mathrm{E}}{\mathrm{LC}_{50} \text { of } \mathrm{C}}\right] \times 100, } \\
\text { Observed TI of the mixture }= & {\left[\frac{\mathrm{LC} \mathrm{C}_{50} \text { of } \mathrm{E}}{\mathrm{LC}_{50} \text { of the mixture }}\right] } \\
& \times 100, \\
\text { Observed TI of the mixture }= & {\left[\frac{\mathrm{LC} \mathrm{LC}_{50} \text { of } \mathrm{E}}{\mathrm{LC}_{5} \text { mixture }}\right] } \\
& \times 100,
\end{aligned}
$$

Theoretical TI of the mixture $=$ TI of $\mathrm{E} \times \%$ of $\mathrm{E}$ in the mixture

$$
+ \text { TI of } \mathrm{C} \times \% \text { of } \mathrm{C} \text { in the mixture, }
$$$$
\text { Cotoxicity index }=\left[\frac{\text { observed TI of the mixture }}{\text { theoretical TI of the mixture }}\right]
$$$$
\times 100
$$

where $\mathrm{E}$ represents extract or essential oil of E. camaldulensis and $\mathrm{C}$ represents extract or essential oil of $C$. rigidus.

When one component of the mixture (extract or essential oil of $C$. rigidus for example) causes a low mortality $(<20 \%)$ at all doses tested, cotoxicity index of the combination would be calculated as follows:

$$
\text { Cotoxicity index }=\left[\frac{\mathrm{LC}_{50} \text { of E alone }}{\mathrm{LC}_{50} \text { of the mixture }}\right] \times 100 \text {. }
$$

Then, according to Sun and Johnson [31],

(i) If cotoxicity index is less than 80 , it is considered as antagonistic action

(ii) If cotoxicity index is between 80 and 120 , it is considered as additive action

(iii) If cotoxicity is greater than 120 , it is considered as synergistic action

Synergistic factors were also calculated according to Kalyanasundaram and Das [32] method as follows:

Synergistic factor (SF)

$$
=\frac{\mathrm{LC}_{50} \text { of the plant extract or essential oil alone }}{\mathrm{LC}_{50} \text { of the mixture }} .
$$

Value of $\mathrm{SF}>1$ indicates synergistic action and $\mathrm{SF}<1$ indicates the antagonistic action.

2.7. Statistical Analyses. Data of the corrected mortality percentage of larvae were submitted to analysis of variance (ANOVA) using SPSS (Statistical Package for the Social Sciences) software version 16.0. Mean separation was 
performed using Tukey test $(P=0.05)$. Probit analysis [33] was applied to determine the lethal concentration that caused $50 \%\left(\mathrm{LC}_{50}\right)$ and $95 \%\left(\mathrm{LC}_{95}\right)$ mortality of mosquito larvae.

\section{Results}

3.1. Extraction Yield. The extraction yield of the leaves of two plant species C. rigidus and E. camaldulensis is presented in Table 1 . When extracted with the methanol solvent, the yield obtained from the leaves of C. rigidus $(30.71 \%(w / w))$ was slightly high compared to the yield obtained from the leaves of E. camaldulensis (23.79\% (w/w)). Similarly for essential oils, the yield obtained from the leaves of $C$. rigidus was $1.20 \%(\mathrm{w} / \mathrm{w})$ which was high compared to the yield obtained from the leaves of E. camaldulensis $(0.84 \%(\mathrm{w} / \mathrm{w}))$.

Table 2 presents the result of the phytochemical screening of the methanol extract of $C$. rigidus and $E$. camaldulensis. In the two methanol plant extracts, the six phytochemical constituents targeted including alkaloids, flavonoids, tannins, saponins, terpenoids, and polyphenols were present in variable concentration. In the methanol extract of C. rigidus, alkaloids, saponins, and polyphenols were found in high concentration compared to the other constituents present in the plant. Concerning the methanolic extract of E. camaldulensis, the plant is highly concentrated in tannins and polyphenols.

The mortality percent of the larvae of $A$. gambiae treated with the methanol extracts of $E$. camaldulensis and $C$. rigidus applied in single each and in binary combination and their $\mathrm{LC}_{50}$ as well as $\mathrm{LC}_{95}(\mathrm{ppm})$ values $24 \mathrm{~h}$ postexposure are presented in Table 3. Applied singly or in combination, the methanol extracts of the two plants exerted a significant $(P<0.05)$ toxicity activity against the mosquito larvae and that efficacy augments with the increase in concentration. Tested singly, a significant larval mortality ranging from $0 \%$ at $125 \mathrm{ppm}$ to $98 \%$ at $1000 \mathrm{ppm}\left(F_{(5,18)}=350.96 ; P<0.001\right)$ with $E$. camaldulensis extract and from $83 \%(125 \mathrm{ppm})$ to $100 \%(1000 \mathrm{ppm})\left(F_{(5,18)}=1528.66 ; P<0.001\right)$ with $C$. rigidus extract was recorded. In combination, the mixture E25\%:C75\% caused significantly high mosquito larval mortality ranging from $57 \%$ at $125 \mathrm{ppm}$ to $100 \%$ at $1000 \mathrm{ppm}\left(F_{(5,18)}=671.17 ; P<0.001\right)$ compared to the other combinations. Among the two plant extracts, $C$. rigidus methanol extract $\left(\mathrm{LC}_{50}=39.15 \mathrm{ppm}\right.$ and $\left.\mathrm{LC}_{90}=319.80 \mathrm{ppm}\right)$ was the most potent compared to E. camaldulensis extract $\left(\mathrm{LC}_{50}=408.90 \mathrm{ppm}\right.$ and $\left.\mathrm{LC}_{90}=849.50 \mathrm{ppm}\right)$ when tested on mosquito larvae. However, the combination of the two plant extract lowers the efficacy of $C$. rigidus by increasing the $\mathrm{LC}_{50}$ values (117.91, 183.37, and $106.21 \mathrm{ppm}$ for combinations E75\% : C25\%, E50\% : C50\%, and E25\% : C75\%, respectively) compared to $\mathrm{LC}_{50}$ of $C$. rigidus tested singly.

The synergistic factor and cotoxicity index of the combination of the essential oils of $E$. camaldulensis and $C$. rigidus against the larvae of $A$. gambiae $24 \mathrm{~h}$ posttreatment are presented in Table 4 . From these results, only the combination E. camaldulensis $75 \%$ and C. rigidus $25 \%$ (synergistic factor $=1.031$ and cotoxicity index $=103.177$ (between 80 and 120)) showed an additive action against the larvae of A. gambiae, $24 \mathrm{~h}$ postexposure. The combinations E50\%:C50\% (synergistic factor $=0.389$ and cotoxicity index $=38.969$ (less than 80)) and E50\%: C50\% (synergistic factor $=0.476$ and cotoxicity index $=47.632$ (less than 80 ) were revealed as the bad mixtures since they exhibited each an antagonistic effect against on the mortality of the $A$. gambiae larvae after $24 \mathrm{~h}$ posttreatment.

The percentage mortality of $A$. gambiae larvae treated with the essential oils of E. camaldulensis and C. rigidus applied singly and in binary combination and their $\mathrm{LC}_{50}$ as well as $\mathrm{LC}_{95}$ (ppm) values $24 \mathrm{~h}$ postexposure are presented in Table 5. The essential oil of E. camaldulensis tested singly caused $31 \%$ larval mortality only at the highest tested dose of $200 \mathrm{ppm}$ while the positive control Bi-one exhibited 100\% mortality of A. gambiae larvae. The essential oil of $C$. rigidus tested also singly caused a significant $\left(F_{(5,18)}=376.93\right.$, $P<0.001)$ larval mortality ranging from $0 \%$ at $25 \mathrm{ppm}$ to $88 \%$ at $200 \mathrm{ppm}$. In binary combination, the mixture E75\% : C25\% caused a significant $\left(F_{(5,18)}=389.02 ; P<0.001\right)$ larvicidal activity ranging from $0 \%(25 \mathrm{ppm})$ to $89 \%(200 \mathrm{ppm})$ while the combination E50\%: C50\% exhibited a significant $\left(F_{(5,18)}=404.69 ; P<0.001\right)$ mosquito larval mortality ranging from $0 \%$ at $25 \mathrm{ppm}$ to $43 \%$ at $200 \mathrm{ppm} 24 \mathrm{~h}$ postexposure. The combination showed also a significant $\left(F_{(5,18)}=691.00\right.$; $P<0.001)$ A. gambiae larval mortality ranged from $0 \%$ at $25 \mathrm{ppm}$ to $66 \%$ at $200 \mathrm{ppm}$ after $24 \mathrm{~h}$ posttreatment. In single plant essential oil treatment each, C. rigidus essential oil $\left(\mathrm{LC}_{50}=99.66 \mathrm{ppm}\right)$ was revealed to be the most effective compared to E. camaldulensis essential oil $\left(\mathrm{LC}_{50}=223.03 \mathrm{ppm}\right)$ against the larvae of $A$. gambiae $24 \mathrm{~h}$ postexposure. In binary combination, the mixture $\mathrm{E} 75 \%$ : $\mathrm{C} 25 \%$ with $\mathrm{LC}_{50}=62.87 \mathrm{ppm}$ was the best combination compared to $\mathrm{E} 50 \%$ : $\mathrm{C} 50 \%\left(\mathrm{LC}_{50}=132.58 \mathrm{ppm}\right)$ and $\mathrm{E} 25 \%$ : C75\% $\left(\mathrm{LC}_{50}=115.16 \mathrm{ppm}\right)$ combination against larvae of $A$. gambiae, $24 \mathrm{~h}$ posttreatment.

Table 6 presents the synergistic factor and cotoxicity index of the combination of the essential oils of E. camaldulensis and C. rigidus against the larvae of $A$. gambiae, $24 \mathrm{~h}$ posttreatment. The combination $75 \%$ of E. camaldulensis essential oil with $25 \%$ of C. rigidus essential oil (E75\% : C25\%) with synergistic factor of $2.709(>2)$ and the cotoxicity index of 270.908 (>120) significantly optimized the efficacy of the combination generating a synergistic efficacy against mosquito larvae assayed. The combinations E. camaldulensis $50 \%$ and C. rigidus $50 \%$ (synergistic factor $=1.039$ and cotoxicity index $=103.908)$ as well as E. camaldulensis 25\% and C. rigidus 75\% (synergistic factor $=1.004$ and cotoxicity index $=100.428$ ) exhibited an additive action against the larvae of $A$. gambiae $24 \mathrm{~h}$ posttreatment.

\section{Discussion}

In the insect pest control agent research, the insecticide combination approach is encouraged not only to optimize the efficacy of the insecticide products but also to solve the problem of insect resistance and might apparently preserve efficacy for the insecticide product for many years. Only one action among additive, synergistic, or antagonistic effect is expected in the combination of drug or insecticide [34], and 
TABLE 1: Methanol extract and essential oil extraction yields of C. rigidus and E. camaldulensis.

\begin{tabular}{lccc}
\hline Plant products & Plant species & Plant material weight used $(\mathrm{g})$ & Yield $(\%)$ \\
\hline \multirow{2}{*}{ Methanol extract } & C. rigidus & 250 & 30.71 \\
& E. camaldulensis & 250 & 23.79 \\
\hline \multirow{2}{*}{ Essential oils } & C. rigidus & 200 & 1.20 \\
& E. camaldulensis & 200 & 0.85 \\
\hline
\end{tabular}

TABLe 2: Phytochemical components of the methanol extracts of C. rigidus and E. camaldulensis.

\begin{tabular}{lcccccc}
\hline Extracts & Alkaloids & Flavonoids & Tannins & Saponins & Terpenoids & Polyphenols \\
\hline C. rigidus & +++ & ++ & + & +++ & + & +++ \\
E. camaldulensis & + & ++ & +++ & + & + & +++ \\
\hline
\end{tabular}

$+=$ present at low concentration, $++=$ present at moderate concentration, and $+++=$ present at high concentration.

TABLE 3: Mortality percent of A. gambiae larvae treated with the combination of methanol extracts of E. camaldulensis and C. rigidus and $\mathrm{LC}_{50}$ as well as $\mathrm{LC}_{95}(\mathrm{ppm})$ values $24 \mathrm{~h}$ postexposure.

\begin{tabular}{|c|c|c|c|c|c|c|}
\hline Combinations & Conc (ppm) & $\%$ mortality & Slope \pm SE & LC $_{50}($ LFL-UFL) $(\mathrm{ppm})$ & $\mathrm{LC}_{95}$ (LFL-UFL) (ppm) & $x^{2}$ \\
\hline E100\% & $\begin{array}{c}0 \\
125 \\
250 \\
500 \\
1000 \\
\text { Bi-one } \\
F_{(5,18)} \\
\end{array}$ & $\begin{array}{c}0.00 \pm 0.00 \mathrm{D} \\
0.00 \pm 0.00 \mathrm{D} \\
15.00 \pm 3.00 \mathrm{C} \\
66.00 \pm 5.29 \mathrm{~B} \\
98.00 \pm 1.15 \mathrm{~A} \\
100 \pm 0.00 \mathrm{~A} \\
350.96^{* * *} \\
\end{array}$ & $5.18 \pm 0.22$ & $408.90(384.79-434.53)$ & $849.50(769.31-959.86)$ & $34.93^{* *}$ \\
\hline $\mathrm{E} 75 \%: \mathrm{C} 25 \%$ & $\begin{array}{c}0 \\
125 \\
250 \\
500 \\
1000 \\
\text { Bi-one } \\
F_{(5,18)} \\
\end{array}$ & $\begin{array}{c}0.00 \pm 0.00 \mathrm{D} \\
47.00 \pm 2.51 \mathrm{C} \\
91.00 \pm 2.51 \mathrm{~B} \\
97.00 \pm 1.91 \mathrm{AB} \\
98.00 \pm 1.15 \mathrm{AB} \\
100 \pm 0.00 \mathrm{~A} \\
560.70^{* * *} \\
\end{array}$ & $2.93 \pm 0.17$ & $117.91(81.28-147.90)$ & $426.97(329.72-673.50)$ & $133.33^{* * *}$ \\
\hline E50\% : C50\% & $\begin{array}{c}0 \\
125 \\
250 \\
500 \\
1000 \\
\text { Bi-one } \\
F \\
\end{array}$ & $\begin{array}{c}0.00 \pm 0.00 \mathrm{D} \\
17.00 \pm 1.91 \mathrm{C} \\
92.00 \pm 2.58 \mathrm{~B} \\
96.00 \pm 1.63 \mathrm{~A} \\
100 \pm 0.00 \mathrm{~A} \\
100 \pm 0.00 \mathrm{~A} \\
943.83^{* * *}\end{array}$ & $4.94 \pm 0.23$ & $183.37(167.85-199.15)$ & $394.28(346.73-469.01)$ & $57.66^{* * *}$ \\
\hline E25\% : C75\% & $\begin{array}{c}0 \\
125 \\
250 \\
500 \\
1000 \\
\text { Bi-one } \\
F_{(5,18)} \\
\end{array}$ & $\begin{array}{c}0.00 \pm 0.00 \mathrm{D} \\
58.00 \pm 2.58 \mathrm{C} \\
93.00 \pm 1.91 \mathrm{~B} \\
98.00 \pm 2.00 \mathrm{AB} \\
100 \pm 0.00 \mathrm{~A} \\
100 \pm 0.00 \mathrm{~A} \\
671.17^{* * *} \\
\end{array}$ & $3.46 \pm 0.24$ & $106.21(82.49-124.98)$ & $317.17(265.39-422.31)$ & $65.63^{* * *}$ \\
\hline $\mathrm{C} 100 \%$ & $\begin{array}{c}0 \\
125 \\
250 \\
500 \\
1000 \\
\text { Bi-one } \\
F_{(5,18)}\end{array}$ & $\begin{array}{c}0.00 \pm 0.00 \mathrm{D} \\
83.00 \pm 1.91 \mathrm{C} \\
91.00 \pm 1.00 \mathrm{~B} \\
98.00 \pm 1.15 \mathrm{~A} \\
100 \pm 0.00 \mathrm{~A} \\
100 \pm 0.00 \mathrm{~A} \\
1528.66^{* * *}\end{array}$ & $1.80 \pm 0.18$ & $39.15(24.95-53.24)$ & $319.80(278.04-380.77)$ & $16.67^{\mathrm{ns}}$ \\
\hline
\end{tabular}

Mean of mortality \pm standard deviation within a column followed by the same letter did not differ significantly according to Tukey test $(P=0.05) ;{ }^{\text {ns }} P>0.05$; ${ }^{* *} P<0.01 ;{ }^{* * *} P<0.001$; LC = lethal concentration; LFL: lower fiducial limit; UFL: upper fiducial limit; Bi-one = positive control tested at 1000 ppm; number of replicates: 4 . E100\%, $75 \%, 50 \%, 25 \%$, and $0 \%=$ E. camaldulensis $100 \%, 75 \%, 50 \%, 25 \%$, and $0 \%$, respectively; $\mathrm{C} 100 \%, 75 \%, 50 \%, 25 \%$, and $0 \%=C$. rigidus $100 \%, 75 \%, 50 \%, 25 \%$, and $0 \%$, respectively. 
TABLE 4: Synergistic factor and cotoxicity index of the combination of the methanol extracts of E. camaldulensis and C. rigidus.

\begin{tabular}{lcccc}
\hline Combinations & $\mathrm{LC}_{50}(\mathrm{ppm})$ & Synergistic factor & Cotoxicity index & Type of action \\
\hline E100\%:C0\% & 408.90 & - & - & - \\
$\mathrm{E} 75 \%: \mathrm{C} 25 \%$ & 117.91 & 1.031 & 103.177 & Additive \\
$\mathrm{E} 50 \%: \mathrm{C} 50 \%$ & 183.37 & 0.389 & 38.969 & Antagonistic \\
$\mathrm{E} 25 \%: \mathrm{C} 75 \%$ & 106.21 & 0.476 & 47.632 & Antagonistic \\
$\mathrm{E} 0 \%: \mathrm{C} 100 \%$ & 39.15 & - & - & - \\
\hline
\end{tabular}

$\mathrm{E} 100 \%, 75 \%, 50 \%, 25 \%$, and $0 \%=$ E. camaldulensis $100 \%, 75 \%, 50 \%, 25 \%$, and $0 \%$, respectively; C100\%, $75 \%, 50 \%, 25 \%$, and $0 \%=C$. rigidus $100 \%, 75 \%, 50 \%$, $25 \%$, and $0 \%$, respectively.

TABLE 5: Mortality percent of A. gambiae larvae treated with the combination of the essential oils of E. camaldulensis and C. rigidus and LC ${ }_{50}$ as well as $\mathrm{LC}_{95}(\mathrm{ppm})$ values $24 \mathrm{~h}$ postexposure.

\begin{tabular}{|c|c|c|c|c|c|c|}
\hline Combinations & Conc (ppm) & $\%$ mortality & Slope \pm SE & $\mathrm{LC}_{50}(\mathrm{LFL}-\mathrm{UFL})(\mathrm{ppm})$ & $\mathrm{LC}_{95}(\mathrm{LFL}-\mathrm{UFL})(\mathrm{ppm})$ & $x^{2}$ \\
\hline E100\% & $\begin{array}{c}0 \\
25 \\
50 \\
100 \\
200 \\
\text { Bi-one } \\
F_{(5,18)} \\
\end{array}$ & $\begin{array}{c}0.00 \pm 0.00 \mathrm{C} \\
0.00 \pm 0.00 \mathrm{C} \\
0.00 \pm 0.00 \mathrm{C} \\
0.00 \pm 0.00 \mathrm{C} \\
31.00 \pm 3.00 \mathrm{~B} \\
100.0 \pm 0.00 \mathrm{~A} \\
1729^{* * *}\end{array}$ & $7.35 \pm 0.40$ & $223.03(213.51-233.14)$ & $337.17(345.86-410.84)$ & $24.54^{\mathrm{ns}}$ \\
\hline E75\% : C25\% & $\begin{array}{c}0 \\
25 \\
50 \\
100 \\
200 \\
\text { Bi-one } \\
F_{(5,18)} \\
\end{array}$ & $\begin{array}{c}0.00 \pm 0.00 \mathrm{D} \\
0.00 \pm 0.00 \mathrm{D} \\
50.00 \pm 4.16 \mathrm{C} \\
81.00 \pm 2.51 \mathrm{~B} \\
89.00 \pm 3.41 \mathrm{~B} \\
100.0 \pm 0.00 \mathrm{~A} \\
389.02^{* * *}\end{array}$ & $3.40 \pm 0.13$ & $62.87(52.48-74.23)$ & $191.03(149.12-278.02)$ & $165.60^{* * *}$ \\
\hline $\mathrm{E} 50 \%: \mathrm{C} 50 \%$ & $\begin{array}{c}0 \\
25 \\
50 \\
100 \\
200 \\
\text { Bi-one } \\
F_{(5,18)} \\
\end{array}$ & $\begin{array}{c}0.00 \pm 0.00 \mathrm{D} \\
0.00 \pm 0.00 \mathrm{D} \\
29.00 \pm 4.43 \mathrm{C} \\
38.00 \pm 2.58 \mathrm{BC} \\
43.00 \pm 1.91 \mathrm{~B} \\
100.0 \pm 0.00 \mathrm{~A} \\
404.65^{* * *}\end{array}$ & $2.42 \pm 0.09$ & $132.58(102.77-176.29)$ & $632.22(397.71-1460.60)$ & $256.36^{* * *}$ \\
\hline $\mathrm{E} 25 \%: \mathrm{C} 75 \%$ & $\begin{array}{c}0 \\
25 \\
50 \\
100 \\
200 \\
\text { Bi-one } \\
F_{(5,18)} \\
\end{array}$ & $\begin{array}{c}0.00 \pm 0.00 \mathrm{E} \\
0.00 \pm 0.00 \mathrm{E} \\
20.00 \pm 1.63 \mathrm{D} \\
43.00 \pm 3.41 \mathrm{C} \\
66.00 \pm 2.58 \mathrm{~B} \\
100.0 \pm 0.00 \mathrm{~A} \\
691.00^{* * *}\end{array}$ & $3.07 \pm 0.11$ & $115.16(101.71-130.69)$ & $394.96(318.00-528.64)$ & $84.48^{* * *}$ \\
\hline C100\% & $\begin{array}{c}0 \\
25 \\
50 \\
100 \\
200 \\
\text { Bi-one } \\
F_{(5,18)} \\
\end{array}$ & $\begin{array}{c}0.00 \pm 0.00 \mathrm{E} \\
0.00 \pm 0.00 \mathrm{E} \\
21.00 \pm 3.41 \mathrm{D} \\
40.00 \pm 3.65 \mathrm{C} \\
88.00 \pm 3.65 \mathrm{~B} \\
100.0 \pm 0.00 \mathrm{~A} \\
376.93^{* * *}\end{array}$ & $3.73 \pm 0.14$ & $99.66(89.32-111.32)$ & $274.76(229.71-348.72)$ & $81.32^{* * *}$ \\
\hline
\end{tabular}

Mean of mortality \pm standard deviation within a column followed by the same letter did not differ significantly according to Tukey test $(P=0.05) ;{ }^{\text {ns }} P>0.05$; ${ }^{* * *} P<0.001$; LC: lethal concentration; LFL: lower fiducial limit; UFL: upper fiducial limit; Bi-one = positive control tested at 1000 ppm; number of replicates: 4. $\mathrm{E} 100 \%, 75 \%, 50 \%, 25 \%$, and $0 \%=$ E. camaldulensis $100 \%, 75 \%, 50 \%, 25 \%$, and $0 \%$, respectively; $\mathrm{C} 100 \%, 75 \%, 50 \%$, $25 \%$, and $0 \%=$ C. rigidus $100 \%, 75 \%$, $50 \%, 25 \%$, and $0 \%$, respectively.

the aim of any plant combination assay carried out is to obtain synergistic action of the mixture. Results from the larvicidal activity showed that extracts or essential oils of E. camaldulensis and $C$. rigidus used singly or in binary combination caused a significant mortality of $A$. gambiae larvae. In the present study, methanol extract of $C$. rigidus tested singly was the most potent against mosquito larvae and its combination with E. camaldulensis extract exhibited antagonistic effects. Nevertheless, previous studies showed synergistic action of plant extracts when blended. Thus, the binary combination of ethanol leaf extracts of Dracaena arborea and Vitex doniana exerted synergistic effects on Anopheles mosquito species [35]. Yankanchi et al. [36] tested individually and in combination with Pongamia glabra seed extract, three leaf plants extracts 
TABLE 6: Synergistic factor and cotoxicity index of the combination of the essential oils of E. camaldulensis and C. rigidus.

\begin{tabular}{lcccc}
\hline Combinations & $\mathrm{LC}_{50}(\mathrm{ppm})$ & Synergistic factor & Cotoxicity index & Type of action \\
\hline $\mathrm{E} 100 \%: \mathrm{C} 0 \%$ & 223.03 & - & - & 270.908 \\
$\mathrm{E} 75 \%: \mathrm{C} 25 \%$ & 62.87 & 2.709 & 103.908 & Synergistic \\
$\mathrm{E} 50 \%: \mathrm{C} 50 \%$ & 132.58 & 1.039 & 100.428 & Additive \\
$\mathrm{E} 25 \%: \mathrm{C} 75 \%$ & 115.16 & 1.004 & - & Additive \\
$\mathrm{E} 0 \%: \mathrm{C} 100 \%$ & 99.66 & - & - \\
\hline
\end{tabular}

E100\%, $75 \%, 50 \%, 25 \%$, and $0 \%=$ E. camaldulensis $100 \%, 75 \%, 50 \%, 25 \%$, and $0 \%$, respectively; $\mathrm{C} 100 \%, 75 \%, 50 \%, 25 \%$, and $0 \%=C$. rigidus $100 \%, 75 \%, 50 \%$, $25 \%$, and $0 \%$, respectively.

Vitex negundo, Clerodendrum inerme, and Gliricidia sepiumagainst fourth-instar larvae of Aedes aegypti and found that, tested individually, C. inerme $\left(\mathrm{LC}_{50}=292.36 \mathrm{ppm}\right)$ was the most toxic while the maximum synergistic activity was found in the combination extracts of $C$. inerme $50 \%$ with P. glabra $50 \%\left(\mathrm{LC}_{50}=195.02 \mathrm{ppm}\right)$ as well as in $50 \%$ $V$. negundo with $50 \%$ P. glabra $\left(\mathrm{LC}_{50}=191.73 \mathrm{ppm}\right)$. Synergistic efficacy of the mixtures of Callitris glaucophylla extracts and Khaya senegalensis extracts at $1: 1$ ratio against the fourth earlier instar larvae of $A$. aegypti and $C$. annulirostris within the first $24 \mathrm{~h}$ [37]. The efficacy of the two plant extracts against mosquito larvae may be due to their richness in alkaloids, flavonoids, tannins, saponins, terpenoids, and polyphenols which have been previously reported to possess insecticidal properties [37]. These toxic phytocompound substances are ingested orally or through cuticle route which might affect insect physiology balance causing death [38].

Mixing E. camaldulensis with C. rigidus essential oils in $3: 1$ ratio showed a synergistic activity when tested against $A$. gambiae larvae in the present investigation. This result corroborates with the findings of Ríos et al. [39] in which the essential oils of Thymus vulgaris tested individually and the combination of Lippia origanoides with Swinglea glutinosa exhibited the highest larvicidal activity on $A$. aegypti larvae. Similarly, results showed that the combinations of essential oils extracted from resin of Aucoumea klaineana, Canarium schweinfurthii, and Dacryodes edulis led to the enhancement of their efficacy and exhibited a significant larvicidal activity against $A$. gambiae [40]. The binary combinations in $1: 1$ ratio of Syzygium aromaticum + Illicium verum, $S$. aromaticum + Trachyspermum ammi, and I. verum $+T$. ammi essential oils showed synergistic interactions among the binary mixtures [41]. Zibaee et al. [42] obtained the best repellent activity with the cream formulation containing a combination blend of Rosemary and Chamomile oils against the A. stephensi and C. pipiens adults. The repellent efficacy of Azadirachta indica oil against A. aegypti was reinforced when sweet basil oil and lemon eucalyptus oil were added to it [43]. Applied in a ratio of $1: 4$, the combination of the two monoterpenoids thymol and carvacrol enhanced the efficacy of the mixture leading to the significant synergistic action against larvae of $C$. pipiens, compared to the efficacy of single compounds tested individually [44]. A study conducted by Pavela et al. [45] revealed the high larvicidal toxicity of the combination mixtures of carvacrol with carvone, carvacrol with 4-allyanisole, and carvacrol with terpineol, when tested against C. quinquefasciatus larvae. Conversely, when combined, garlic and asafoetida essential oils showed antagonistic action compared to their application individually against larvae of C. pipiens and C. restuans [46]. Similar observation was also reported that essential oil of Eucalyptus citriodora used alone showed the best larvicidal activity compared to its combination with Cymbopogon nardus oil against A. gambiae larvae [47]. The toxicity of the plant extract or essential oil combination mixtures might be due the mixture of the phytocomponents found in the mixture and may be acting in synergy as neurotoxic insecticides interfering in the ligand-gated chloride channel of the mosquito larval nervous system or by blocking octopamine or cholinergic receptors, the important target sites of insect pest control [48-50].

\section{Conclusion}

The methanol extracts and essential oils of the two plants tested singly or in binary combinations caused a significant larvicidal activity against $A$. gambiae larvae. Tested individually, the methanol extract and essential oil of $C$. rigidus was revealed to be the most potent compared to E. camaldulensis against mosquito larvae. However, binary combination of the plant methanol extract exhibited antagonistic action while $E$. camaldulensis (75\%) and C. rigidus (25\%) essential oil blend displayed synergistic effect when applied on mosquito larvae. This makes it a more suitable candidate for the development of new potential eco-friendly larvicide for A. gambiae mosquito control in the larvae breeding sites.

\section{Data Availability}

The data used to support the findings of this study are available from the corresponding author upon request.

\section{Conflicts of Interest}

The authors declare that there are no conflicts of interest regarding the publication of this paper.

\section{Authors' Contributions}

L. Younoussa, J. L. Tamesse, and E. N. Nukenine designed the study. L. Younoussa, M. K. Oumarou, A. C. S. Batti, and F. Kenmoe conducted the experiments. L. Younoussa analyzed the data and wrote the first draft of the manuscript. All authors read, corrected, and approved the final version of the manuscript. 


\section{Acknowledgments}

The authors are grateful to Prof. Pierre-Marie Mapongmetsem for the identification of plant species. They acknowledge the Laboratory of Chemistry, Faculty of Science, University of Ngaoundere, Cameroon, for plant extractions and phytochemical screening and are also grateful to the Organization of Coordination for the Fight against Endemic Diseases in Central Africa (OCEAC) for providing mosquito eggs used in the present work.

\section{References}

[1] V. L. Kiggundu, W. P. O’Meara, R. Musoke et al., "High prevalence of malaria parasitemia and anemia among hospitalized children in Rakai, Uganda," PLoS One, vol. 8, no. 12, Article ID e82455, 2013.

[2] WHO, World Malaria Report, World Health Organization, Geneva, Switzerland, 2018.

[3] L. Schwartz, G. V. Brown, B. Genton, and V. S. Moorthy, "A review of malaria vaccine clinical projects based on the WHO rainbow table," Malaria Journal, vol. 11, no. 1, p. 1, 2012.

[4] WHO, Tables of Malaria Vaccine Projects Globally, The Rainbow Tables, 2015, http://www.who.int/immunization/ research/development/Rainbow_tables/en/.

[5] G. J. Devine and M. J. Furlong, "Insecticide use: contexts and ecological consequences," Agriculture and Human Values, vol. 24, no. 3, pp. 281-306, 2007.

[6] M. Sarwar, N. Ahmad, and M. Toufiq, "Host plant resistance relationshiphs in chickpea (Cicer arietinum L.) against gram pod borer (Helicoverpa armigera Hubner)," Pakistan Journal of Botany, vol. 41, no. 6, pp. 3047-3052, 2009.

[7] V. K. Dua, A. C. Pandey, and A. P. Dash, "Adulticidal activity of essential oil of Lantana camara leaves against mosquitoes," Indian Journal of Medical Research, vol. 131, pp. 434-439, 2010.

[8] M. Govindarajan, "Mosquito larvicidal and ovicidal activity of Cardiospermum halicacabum Linn. (Family: Sapindaceae) leaf extract against Culex quinquefasciatus (say.) and Aedes aegypti (Linn.) (Diptera: Culicidae)," European Review for Medical and Pharmacological Science, vol. 15, no. 7, pp. 787-794, 2011.

[9] J. Subramaniam, K. Kovendan, P. Mahesh Kumar, K. Murugan, and W. Walton, "Mosquito larvicidal activity of Aloe vera (Family: Liliaceae) leaf extract and Bacillus sphaericus, against Chikungunya vector, Aedes aegypti," Saudi Journal of Biological Sciences, vol. 19, no. 4, pp. 503-509, 2012.

[10] K. Sukumar, M. J. Perich, and L. R. Boobar, "Botanical derivatives in mosquito control: a review," Journal of American Mosquito Control Association, vol. 72, pp. 210-237, 1991.

[11] F. Candan, M. Unlu, B. Tepe et al., "Antioxidant and antimicrobial activity of the essential oil and methanol extracts of Achillea millefolium subsp. millefolium Afan. (Asteraceae)," Journal of Ethnopharmacology, vol. 87, no. 2-3, pp. 215-220, 2003.

[12] C. C. Joshep, M. M. Ndoils, R. C. Malima, and N. H. M. Nkuniya, "Larvicidal and mosquitocidal extracts, a coumrin, isofavonoids and petrocarpans from Neorautanenia mitis," Transactions for the Royal Society of Tropical Medicine and Hygiene, vol. 98, pp. 451-455, 2004.

[13] A. Ghosh, N. Chowdhury, and G. Chandra, "Plant extracts as potential mosquito larvicides," Indian Journal of Medical Research, vol. 135, pp. 581-598, 2012.
[14] A. Farah, B. Satrani, M. Fechtal, A. Chaouche, and M. Talbie, "Chemical composition, antibacterial and antifungal activities of essential oils from the leaves of Eucalyptus camaldulensis and its natural hybrid (clone 583)," Acta Botanica Gallica (France), vol. 148, no. 3, pp. 183-190, 2011.

[15] J. M. Watt and M. G. Breyer-Brandwijk, The Medicinal and Poisonous Plants of Southern and Eastern Africa, E.\&S. Livingstone, Ltd., London, UK, 2nd edition, 1962.

[16] K. Watanabe, Y. Shono, A. Kakimizu et al., "New mosquito repellent from Eucalyptus camaldulensis," Journal of Agricultural and Food Chemistry, vol. 41, no. 11, pp. 2164-2166, 1993.

[17] S. M. Nishimura, S. Reza, K. Mahnaz et al., "Phytochemistry and larvicidal activity of Eucalyptus camaldulensis against malaria vector, Anopheles stephensi," Asian Pacific Journal of Tropical Medicine, vol. 3, no. 11, pp. 841-845, 2010.

[18] A. Alouani, T. Ababsia, I. Rahal, N. Rehimi, and H. Boudjelida, "Activity evaluation of botanical essential oils against immature mosquitoes of Culex pipiens (Diptera: Culicidae)," Journal of Entomology and Zoology Studies, vol. 5, no. 4, pp. 829-834, 2007.

[19] L. Jirovetz, W. Fleischacker, G. Buchbauer, and M. B. Ngassoum, "Analysis of the essential oils of Callistemon rigidus (Myrtaceae) from cameroun by GC/FID and GC/MS," Scientia Pharmaceutica, vol. 65, pp. 315-319, 1997.

[20] K. G. Praveen, J. Renuka, J. Shweta, and S. Archana, “A review on biological and phytochemical investigation of plant genus Callistimon," Asian Pacifique Journal of Tropical Biomedicine, pp. S1906-S1909, 2012.

[21] Y. S. P. Danga, C. O. Osimone, L. Younoussa, and E. N. Nukenine, "Larvicidal and pupicidal activities of Plectranthus glandulosus and Callistemon rigidus leaf essential oils against three mosquito species," Journal of Mosquito Research, vol. 4, no. 2, pp. 5-14, 2014.

[22] S. P. Y. Danga, E. N. Nukenine, L. Younoussa, C. Adler, and C. O. Esimone, "Efficacy of Plectranthus glandulosus (Lamiaceae) and Callistemon rigidus (Myrtaceae) leaf extract fractions to Callosobruchus maculatus (Coleoptera: Bruchidae)," Journal of Insect Science, vol. 15, no. 1, pp. 139-145, 2015.

[23] M. B. Isman, "Botanical insecticides, deterrents, and repellents in modern agriculture and an increasingly regulated world," Annual Review of Entomology, vol. 51, no. 1, pp. 45-66, 2006.

[24] E. M. Williamson, "Synergy and other interactions in phytomedicines," in Trease and Evans Pharmacognosy, pp. 53-61, Elsevier, Amsterdam, Netherlands, 16th edition, 2009.

[25] J. B. Harborne, Phytochemical Methods. A Guide to Modern Techniques of Plant Analysis, Chapman \& Hall, London, UK, 1973.

[26] G. E. Trease and W. C. Evans, Pharmacognosy, Macmillian Publishers Naturalist, London, UK, 1978.

[27] T. Prashant, K. Bimlesh, K. Mandeep, K. Gurpreet, and K. Harleen, "Phytochemical screening and extraction: a review," Internationale Pharmaceutica Sciencia, vol. 1, no. 1, pp. 98-106, 2011.

[28] WHO, "Report of the World Health Organization," informal consultation on the evaluation and testing of insecticides, World Health Organization, Geneva, Switzerland, 1996.

[29] WHO, Guidelines for Laboratory and Field Testing of Mosquito Larvicides, World Health Organization, Geneva, Switzerland, 2005.

[30] W. S. Abbott, "A method of computing the effectiveness of an insecticide," Journal of Economic Entomology, vol. 18, no. 2, pp. 265-267, 1925. 
[31] Y.-P. Sun and E. R. Johnson, "Synergistic and antagonistic actions of insecticide-synergist combinations and their mode of action," Journal of Agricultural and Food Chemistry, vol. 8, no. 4, pp. 261-266, 1960.

[32] M. Kalyanasundaram and P. K. Das, "Larvicidal and synergistic activity of plant extracts for mosquito control," Indian Journal of Medical Research, vol. 82, pp. 19-23, 1985.

[33] D. J. Finney, Probit Analysis, Cambridge University Press, London, UK, 1971.

[34] A. C. Nelson and T. A. Kursar, "Interactions among plant defense compounds: a method for analysis," Chemoecology, vol. 9, no. 2, pp. 81-92, 1999.

[35] C. V. Nnamani, H. O. Oselebe, and A. Ogbonna, "Effect of leaf extracts of Draceana aborea L. and Vitex doniana sweet on the larvae of Anopheles mosquito," Animal Research International, vol. 5, no. 2, pp. 835-837, 2008.

[36] S. R. Yankanchi, O. V. Yadav, and G. S. Jadhav, "Synergistic and individual efficacy of certain plant extracts against dengue vector mosquito, Aedes aegypti," Journal of Biopesticides, vol. 7, no. 1, pp. 22-28, 2014.

[37] E. A. Shaalan, D. V. Canyon, M. W. F. Younes, H. AbdelWahab, and A. H. Mansour, "Synergistic efficacy of botanical blends with and without synthetic insecticides against Aedes aegypti and Culex annulirostris mosquitoes," Journal of Vector Ecology, vol. 30, no. 2, pp. 284-288, 2005.

[38] R. S. Rattan, "Mechanism of action of insecticidal secondary metabolites of plant origin," Crop Protection, vol. 29, no. 9, pp. 913-920, 2010.

[39] N. Ríos, E. E. Stashenko, and J. E. Duque, "Evaluation of the insecticidal activity of essential oils and their mixtures against Aedes aegypti (Diptera: Culicidae)," Revista Brasileira de Entomologia, vol. 61, no. 4, pp. 307-311, 2017.

[40] L. C. Obame, J. P. Ondo, G. S. Padzys et al., "Ovicidal and larvicidal activities against Anopheles gambiae, antioxidant and antibacterial proprieties of Aucoumea klaineana Pierre, Canarium schweinfurthii Engl and Dacryodes edulis (G. Don) Lam essential oils from Gabon," International Journal of Pharmacology Research, vol. 6, no. 1, pp. 68-75, 2016.

[41] G. N. Pandiyan, N. Mathew, and S. Munusamy, "Larvicidal activity of selected essential oil in synergized combinations against Aedes aegypti," Ecotoxicology and Environmental Safety, vol. 174, pp. 549-556, 2019.

[42] I. Zibaee, H. M. Farahani, J. M. Razi, and M. N. Moghaddam, "Synergistic effect of two medicinal plants in cream formulation on repellency of vector mosquito and rove beetle," Journal of Entomology and Zoology Studies, vol. 4, no. 4, pp. 73-79, 2016.

[43] K. P. Kiplang'at and R. W. Mwangi, "Synergistic repellent activity of plant essential oils against Aedes aegypti on rabbit Skin," International Journal of Mosquito Research, vol. 1, no. 4, pp. 55-59, 2014.

[44] M. R. Youssefi, M. A. Tabari, A. Esfandiari et al., "Efficacy of two monoterpenoids, carvacrol and thymol, and their combinations against eggs and larvae of the west nile vector Culex pipiens," Molecules, vol. 24, no. 10, p. 1867, 2019.

[45] R. Pavela, F. Maggi, R. Iannarelli, and G. Benelli, "Plant extracts for developing mosquito larvicides: from laboratory to the field, with insights on the modes of action," Acta Tropica, vol. 193, pp. 236-271, 2019.

[46] E. J. Mutiri, J. L. Ramirez, B. Zilkowski, L. B. Flor-Weiler, and A. P. Rooney, "Ovicidal and larvicidal effects of garlic and asafoetida essential oils against west nile virus vectors," Journal of Insect Science, vol. 18, no. 2, pp. 1-6, 2018.
[47] L. C. Obame-Engonga, C. Sima-Obiang, R. L. Ngoua-MeyeMisso et al., "Larvicidal and ovicidal properties against Anopheles gambiae, antioxidant and antibacterial activities of the combination of essential oils Eucalyptus citriodora, Cymbopogon giganteus and Cymbopogon nardus from Gabon," Journal of Multidisciplinary Engineering Science and Technology, vol. 4, no. 8, pp. 7887-7894, 2017.

[48] C. M. Priestley, E. M. Williamson, K. A. Wafford, and D. B. Sattelle, "Thymol, a constituent of thyme essential oil, is a positive allosteric modulator of human GABAA receptors and a homo-oligomeric GABA receptor from Drosophila melanogaster," British Journal of Pharmacology, vol. 140, no. 8, pp. 1363-1372, 2003.

[49] F. Tong and J. R. Coats, "Effects of monoterpenoid insecticides on $\left[{ }^{3} \mathrm{H}\right]$-TBOB binding in house fly GABA receptor and ${ }^{36} \mathrm{Cl}^{-}$ uptake in American cockroach ventral nerve cord," Pesticide Biochemistry and Physiology, vol. 98, no. 3, pp. 317-324, 2010.

[50] V. López, M. Cascella, G. Benelli, F. Maggi, and C. GómezRincón, "Green drugs in the fight against Anisakis simplexlarvicidal activity and acetylcholinesterase inhibition of Origanum compactum essential oil," Parasitology Research, vol. 117, no. 3, pp. 861-867, 2018. 